\title{
Releasing the potential of Shakespearean comic book adaptations in the classroom: A case study of Romeo and Juliet
}

\section{Introduction}

While comics have been used to support teaching practice for many years (for example, Hutchinson, 1949), their use has become more widespread in recent years and there are examples of teachers using comics to teach a wide range of subjects (for example Aiken, 2010; Gerde and Foster, 2007; Hosler and Boomer, 2011). In particular, teachers of English are increasingly using classic works of literature retold in a comic or graphic novel format to introduce students to, and provide alternative views on, what could be regarded as less accessible texts, for example, Beowulf (Hinds, 2007), The Odyssey (Hinds, 2010) and Crime and Punishment (Mairowitz et al, 2009). Unsurprisingly, given the requirements to teach Shakespeare in UK schools and elsewhere (for example, Department for Education, 2013; Board of Studies NSW, 2004), adaptations of Shakespeare's plays have become particularly popular. It would seem that Shakespeare's centrality to the curriculum, 'guarantees a market' (Lanier, 2010: 105). However, despite the many creative examples using comics in education, within literature teaching, attention seems focused on attempting to engage students and make works more accessible, especially to 'reluctant readers'. Comic book adaptations are often seen as a stepping stone to the 'real' text, a way of introducing young people to works whose language, settings and complexity may be off-putting (for example, Pomfrett, 2011). However, the axiom that comics are a way to engage students who are not ordinarily keen readers has been disputed when investigated more rigorously (Gibson, 2008).

The first section of this article discusses adaptation and comics, in particular the adaptation of Shakespearean plays. This is follow by an examination of the role of the comics reader, drawing on reader response theory. The second section of the article uses this theoretical framework to perform close readings of two key scenes from Romeo and Juliet as they are portrayed in four diverse comic book adaptations. The final discussion section draws on this analysis to consider the variety of ways in which comic book adaptations such as those studied may act as an effective pedagogical device to support young people of varying abilities studying Shakespeare's plays and to discuss whether these texts have a value in their own right, or are to be regarded simply as a crutch which can be discarded as soon as it is no longer needed. 


\section{Adaptation and comics}

As Hutcheon points out, 'an adaptation is likely to be greeted as minor and subsidiary and certainly never quite as good as the "original"". (Hutcheon, 2012: xiv). Furthermore, she highlights the fact that some formats are 'more acceptable than others' (Hutcheon, 2012: 3), with 'high culture' arts such as opera and ballet being privileged over popular culture formats, which would undoubtedly include comics. As Myklebost (2013) argues, despite the number and variety of examples now available, comics adaptations have not been sufficiently studied, especially when the original texts are theatre plays. Furthermore, although parallels are often made between film and comics, comparisons between theatre and comics are less frequent.

Possibly the most crucial difference between the performance of a play and a written text is that the latter lacks the dimension of time. It is left to the reader to determine the speed of the action. In doing this, they are guided by the author or creator. In a comic, the creator commonly guides the reader through the use of images, for example using speed lines to indicate motion, and also through the layout of a page. As the comics reader must read unfamiliar words and also take account of the images presented, the speed of retelling may be slower than the equivalent scene in a theatrical production. Another obvious difference between a written text and a stage production is that the text is silent; it is up to the reader to decide how the words are spoken and what emotion is conveyed by the character as they speak. However, the comics creator, again, helps the reader through the body language of the character and symbols such as lines drawn around the head to indicate shock or surprise or sweat droplets around a character's head to indicate hard work or stress. The position and design of the speech bubbles can also be used to indicate how the character might be expected to say the words. Other sounds, such as music and the sound of fighting, might be shown through the use of glyphs such as music notes and sound effects like 'ching' and 'klang'.

A further difference between a stage adaptation and a comic is that comics are static; there is no continuous flow of action. Perhaps the closest theatrical equivalent would be a series of tableaux. Comics present the reader with a series of images and it is left to the reader to fill the 'gaps', or absences of connections, between the frames in order to make sense of the text. In some instances, these gaps may represent fractions of a second, while in other cases, much 
longer periods of time may elapse between frames. Thus, it is not just which words and images the creator choses to include which are important; it can be argued that what is omitted (left in the gutter) is as significant as what is included and it is the reader's interpretation of these 'gaps' which allow them to make sense of the story. The resulting ambiguity and the possibility for multiple interpretations is what Myklebost (2013) refers to as the 'slippery' nature of comic book adaptations.

When producing a comic which is to closely follow the narrative of another text, as in the examples studied here, the adaptor decides how to edit the text, while the illustrator (who may be the same individual) decides how to depict each scene; how to portray the characters; how to position the speech bubbles and so forth. Just as it is usual for performances of plays to be shortened to fit the requirements of theatrical of film production, the text is usually shortened to make it more suitable for a comic book presentation. For example, this may mean focusing on the crucial emotional points of the story to create tension. As the works studied illustrate, however, adaptors can have very different ideas about which elements of the text to focus on and illustrators may choose to highlight particular aspects of the story in their images or to depict events from a certain viewpoint. Crucially, a comics illustrator decides how to make use of the text and incorporate it as an integral part of the image, not simply depict it as a picture storybook illustrator might do.

\section{Adapting Shakespeare}

The prevalence of Shakespeare on school curricula means there is no shortage of comic book adaptions of his plays and, in many cases, publishers also provide supporting material for teachers, such as lesson plans and student worksheets. The focus of this article is on the 'intertextual' aspects of adaptation, that is, the ways in which Shakespeare's play is adapted into another medium. However, it is also important to be aware of the implications of 'transtextual' elements such as conventions of comics or manga formats, examples of which are described above, and 'extratextual' features such as editorial guidelines for series titles (Franco, 2011).The four examples selected for study in this article have been chosen to allow comparison of the variety of approaches to adapting Shakespeare to support school curricula, including Western-influenced and manga styles, and series clearly aimed at teachers as well as works of interest to a wider audience.

Although curriculum demands have resulted in an increase in the number of adaptations of Shakespeare, not only in comics, but also in other formats including film and multimedia 
resources, adapting Shakespeare's plays to make them more accessible for children is not a new phenomenon. In the early nineteenth century, Charles and Mary Lamb produced their Tales from Shakespeare. These simplified retellings of the best known plays were later illustrated by Arthur Rackham (Lamb and Lamb, 1994). From the 1940s onwards, Albert Kanter's Classic Comics series, later to become Classics Illustrated, included comic book versions of a number of Shakespeare's plays, including Julius Caesar, Hamlet, Macbeth and Romeo and Juliet. Despite the explicit educational purpose of this series, the notion of producing comic book adaptions of Shakespeare was scorned by many contemporary educators (Sawyer, 1987, p.7). The 1980s saw notable adaptations of Shakespeare in comic form with the publication of six titles by Oval Projects. The twenty-first century, though 'has seen an expansion in the number of educational series that adapt Shakespeare to comic book form (Lanier, 2010). Lanier (2010) describes the 'teening' of Shakespeare in films of the 1990s and there is evidence of a similar process in comic book adaptations since this period. In addition to reprints of Classics Illustrated and Oval Projects titles, numerous comics have been published based, to a greater or lesser extent, on Shakespearean plays including Romeo and Juliet, for example, De Col and McCreery's Kill Shakespeare series; Romeo and Juliet: The War (Work et al, 2011); She Lies with Angels (Austen and Larroca, 2004); Romeo X Juliet anime and accompanying manga adaptation. The focus of this article, however, is on recent adaptations, likely to be used within schools, which preserve the original storyline, albeit sometimes abridged.

Looking at the way in which comic book adaptations, especially those more obviously aimed at schools, are described, these texts appear to have two linked aims: to make potentially offputting texts more appealing to teenagers by presenting them in a more familiar format; and to simplify more difficult texts for younger readers, and particularly 'reluctant readers'. The extent to which teachers' or publishers' preconceptions about the suitability of particular texts for certain students contribute to the phenomenon of the 'reluctant reader' is open to debate, but there appears to be an assumption, among publishers and others, that the majority of young people are reluctant to read, but are highly proficient in the interpretation of visual information. This stretches back to Arthur Kutner who, according to the Illustrated Classics Collectors' Club Newsletter, 'merely wanted to place the original books in a form more accessible to a generation that was beginning to recoil from the linearity of printed matter into more immediate less cerebral medium' (Sawyer, 1987: 20). More recently, the Shakespeare Comic Book Series, 'was created in response to a simple question: how can we 
present serious literature to a generation of school students that is intensely visually aware but often reluctant to read?' (Shakespeare Comic Books, nd). Similarly, it is claimed that the Graphic Shakespeare adaptations, "will capture the attention of reluctant readers, make great supplements to more traditional sources, and will help readers imagine the action like never before' (ABDO, nd). However, this assumption that comics represent an 'easy option' is highly questionable. The following section examines in greater detail the complexity of comics, demonstrating further why they are not necessarily the simple, straightforward medium they might first appear.

\section{The comics reader}

A common method in rhetorical analysis seeks to map the 'rhetorical triangle'. This involves a tripartite examination of the interaction, meaning construction and generation of emotional responses between the arguer, the argument and the audience through discourse (Richardson, 2006; Weaver, 2011). In relation to comics, this involves a consideration of the position of the producer of the comic, the content of the comic and its meanings, and the reception of the comic by various audience groups. The interactions between these three elements of the rhetorical triangle involve historical, social and cultural considerations. This makes the role of the comic book reader a crucial one; meaning does not reside in the text itself, but is created through the interaction of reader, image and text.

The comics reader has been described by McCloud as the author's 'silent accomplice' and 'equal partner in crime' (McCloud, 1994: 68). This demonstrates Rosenblatt's transactional theory of reading, in which a literary work is conceived not as an object, but as an experience shaped by the reader under the guidance of the text. This guidance takes the form of 'clues' (Allen, 1998). Rosenblatt proposed that a 'literary work exists in a live circuit set up between reader and text' (Rosenblatt, 1994: 25). In reading a comic, however, the situation is more complex as there are three components: reader, written text and visual language. Each person does not only have their own reaction to a word based on personal experience and background (Iser, 1989:252), but also their own individual reaction to each icon in a picture. The reader creates an overall meaning by relating both the words and images to their own experiences. The result is that there is no single 'correct' or absolute meaning, but a series of more or less equally valid alternative interpretations. Furthermore, for the reader meaning is not fixed, it can change during the course of reading and can be modified after the work has been read. The relationship between reader and text is therefore not a linear one; it can be 
thought of as a series of events. Thus, comics as a form require a substantial degree of reader participation for narrative interpretation; thus fostering a form of interpretive intimacy (McCloud, 1994: 69).

Of course, the author can guide the reader, for example, encouraging them to view an image in a certain way according to features of the layout, such as looking up at something to make it appear oppressive or frightening. However, even when such suggestions are offered, the reader still has some latitude in the way in which they construct meaning from the image. There are similarities between this notion and Barthes' readerly text, and writerly text. The readerly text invites the reader to accept a superficial reading of the text, where the meanings are made explicit by the author, and the reader becomes passive. In contrast, a writerly text, which might include comics, challenges the reader to make sense of its various textual constructs and to inscribe their own meanings onto the various layers of subtext (Barthes, 1974).

To read comics successfully, the reader has to understand particular conventions such as speed lines to indicate motion. Regular readers of comics naturally become more skilled in interpretation with practice. Lefevre describes the 'recurring dominant techniques (such as line drawing, use of balloons and tiers, recurring dominant types of narratives and characters (funny animals, superheroes, mischief gags...)' (Lefevre, 2010: 35), all of which can be studied in an analysis. In visual communication, meaning is formed through a combination of universal icons, such as a circle with two dots and a line to represent a face, and culturallybased conventions, such as dollar signs to represent money (Bamford, 2003). To read comics, readers also have to understand particular conventions such as speed lines and balloons to indicate speech. Regular readers of comics naturally become more skilled in interpretation with practice. Eisner refers to the 'series of repetitive images and symbols' which comics employ which when used repeatedly to convey similar ideas, 'become a language' (Eisner, 1985: 8).

Crucially, as a series of static images, comics omit far more visual information than they include and the panels can be seen as 'visual fragments' (Greonsteen 2007; 10). Key to the analysis of comics, therefore, is Iser's (1989) notion of 'gaps' in the text, absences of connections that readers must fill in order to make sense of the text. In comics, these 'gaps' take the particularly striking form of gutters between frames. Comics possess an inherent 
'incompleteness' and 'indeterminacy' which 'urges readers to take up the constitutive act of interpretation' (Hatfield, 2005: xiii). It is the reader who decides what to include or omit based on a highly individual range of factors. As Iser (1989) describes, unlike the hypothetical Implied Reader, the Actual Reader may not fill the gaps and complete meaning in the text in the way in which the author intended. On the contrary, the Actual Reader should be allowed a degree of freedom in their interpretation of the text. As Hatfield acknowledges, this freedom means that comics can seem 'radically fragmented and unstable', but argues that this 'tension' is their 'great strength' (Hatfield 2005: 36). The tension Hatfield describes is created by the way in which various interpretative options 'must be played against each other' (Hatfield 2005: 36) as readers make judgements and respond to the visual and textual messages of the comic.

Comics differ from illustrated, or picture, books in that the images are an essential element; they are not supplementary as in an illustrated text, but play an integral role in the telling of the story. As Labio states that the genre, 'does not privilege text over image' (Labio, 2011: 124). The use of both text and image offers a 'combination of linguistic and visual codes' (Groensteen, 2007: 3), which is often described as creating more than the sum of its parts. This suggests that the analysis of comics has to address both image and text, and preferably as one. Furthermore, although image and text need to work together in a comic, this does not necessarily mean that the two components always convey the same message. Narrative polyphony (Lewis, 2010) occurs when, for example, the picture shows the character's outward behaviour, while a thought bubble conveys his true feelings. To comprehend the comic, the reader needs to take account of both. This process of presenting the multiple messages simultaneously would seem to be well-suited to the interpretation of complex, layered texts such as Shakespeare.

This means that comics, as a medium, can place "a great demand on cognitive skills" (Chute, 2008) as the way in which information is coded in comics can be highly complex. Readers are required to interpret not only text, but also images and must, therefore, negotiate two systems of codes, or 'dual narrative tracks' (Chute, 2008), which sometimes function independently, and at other times interact. As a hybrid word-image format, therefore, comics require the reader to develop a number of strategies to make sense of the various possibilities presented. 
Of course, when the reader is faced with an adaptation of a familiar story, perhaps the most obvious way by which they might complete the narrative is by reference to the original work; Hutcheon claims this process is 'inevitable' (Hutcheon, 2012: 121). However, this relies on the reader being familiar with the original narrative. Although the adaptations may work as texts for 'unknowing' audiences as well as 'knowing' ones (Hutcheon, 2012), young people less familiar with Shakespeare's plays may fill in the gaps in ways which differ from those of adult readers more familiar with the original works or at least with the 'generally circulated cultural memory' associated with them (Ellis, 1982, p.3). Having outlined an approach to the analysis of comics, the following section demonstrates how this can be applied in practice by comparing four adaptations of Romeo and Juliet.

\section{Adaptations of Romeo and Juliet}

With two teenage lovers as the central protagonists, frequent theatre productions, accessible film adaptations and famous scenes and lines likely to be familiar even to those with no formal knowledge of Shakespeare, Romeo and Juliet is among the most frequently taught of Shakespeare's texts, and is often used as a first introduction to studying Shakespeare. The story of the doomed love affair between members of two warring families has found its way into almost every aspect of culture, from Prokofiev's ballet score to High School Musical. The four adaptations compared in this article illustrate the variety of ways in which Shakespeare has been reinterpreted in a comics format, while retaining the overall narrative of the original play.

Classical Comics (McDonald et al, 2009) offers the most conventional representation among the comics studied, drawing markedly on long-standing comic traditions of the western hemisphere. Production follows the mass market approach of employing different artists for line work, colouring and lettering and the finished product is printed in full colour on glossy paper. As Neill (2013) points out, the visual style of the artwork in the Classical Comics adaptation is 'realistic, bordering on being naturalistic'. He argues that this encourages the reader to view the play as a classic text which conveys a weighty message. 'However, the visual elements of this comic 'become largely invisible'; it is the text which takes precedence.

Classical Comics offer three different versions of the text for each of the titles in its Shakespeare line: the complete and unabridged Original Text version (analysed in this 
article); the simplified Plain Text which translates Shakespeare's dialogue verse-for-verse into modern English (both British and American versions); and the highly simplified Quick Text, which reduces the dialogue to as few words as possible. Each of these three versions have the same illustrations, but for example, 'Be not her maid, since she is envious; her vestal livery is but sick and green, and none but fools do wear it; cast it off' in the original text becomes, 'Don't worry about the moon's jealousy. It is sick and green - the colour of fools and virgins. Get rid of it!' in the plain text and, 'it is jealous of your beauty' in the quick text. Classical Comics also produce a resource book with accompanying $\mathrm{CD}$ for teachers which contains worksheets on topics such as structure, listening, understanding, character and motivation and literacy techniques.

UK publisher SelfMadeHero's Manga Shakespeare line, which currently offers versions of fourteen of Shakespeare's plays, is another model driven by the perceived needs of teachers. The company's website hosts teaching resources including glossaries, plot synopses and digital teaching resources; defends the pedagogical worth of manga; and advertises teacher workshops. This is one of the few series for the educational market which acknowledges the potential of comic books to support 'students exploring complex ideas' as well as 'those challenged by conventional reading' (SelfmadeHero, nd). Manga Shakespeare uses the original text in an abridged form, focusing on key scenes, but in common with many film and stage adaptations from the last three decades (Lanier, 2010), updates the setting of the play. Thus, Verona becomes a street in the fashionable Shibuya district of Tokyo and the presentday Romeo and Juliet are caught up in a bitter feud between two Yakuza families (Japan's 'mafia').

Some forms of manga are read very quickly, perhaps less than four seconds per page (Allen and Ingulsrud, 2003) and the plots are often non-linear. Consequently, the dialogue in Manga Shakespeare is shortened much more than in other adaptations, giving a faster pace to the story. Overall, this text follows many of the usual manga conventions; the style of drawing is consistently manga-like and it includes the use of manga iconography such as chibi. ${ }^{\mathrm{i}}$ Furthermore, this adaptation often uses unattributed speech bubbles that require the reader to look at the position of the words on the page in order to determine who is speaking. However, while retaining a number of elements of Japanese manga, the Manga Shakespeare series has clearly been produced for a western audience; making it more accessible to readers without 
previous experience of manga, for instance, the action flows from left to right across the page and the book is read from 'front to back'.

Shakespeare's Romeo and Juliet: The Manga Edition (Sexton and Lin, 2008) is one in a series of four by the same adaptor, although working with different artists. Like the Classical Comics version, the Manga Edition is set in fourteenth or fifteenth century Verona. While retaining some elements of manga, such as irregularly shaped panels, the Manga Edition, is a western interpretation of manga. The style of drawing shifts throughout the book. In general, more emotional scenes tend to be drawn in a more manga-like style, while the prosaic scenesetting action usually follows western drawing tradition.

Gareth Hinds' (2013) adaptation of Romeo and Juliet follows his earlier adaptations of King Lear (Hinds, 2009) and The Merchant of Venice (Hinds, 2008), as well as other classic works of literature. The setting for this adaption is early seventeenth century Verona and Hinds bases the scenes closely on actual features of the city. The costumes are in the style of the seventeenth century, but altered to indicate the rebellion of the younger generation, for example, through shorter skirts and tattoos. He also introduces multiracial characters, but in the introduction, stresses that this is to imply the universality of the story rather than an indication of racial conflict. Hinds abridges the text 'as sensitively and faithfully as possible' (Hinds, 2013: 131). The illustrations are in full colour and the layout is simple and clean, although perhaps a little less adventurous in style than some of Hinds' work. He clearly draws on European comic conventions, but also incorporates elements of manga, most noticeably in the sword fight scenes.

In order to compare the approaches taken within these four diverse interpretations and to explore various ways in which these could be used to support young people studying Romeo and Juliet, the remainder of this article will focus on the analysis of two key scenes from the play which feature in all four adaptations.

\section{Act 4 Scene 3: Juliet drinks the vial of potion}

In her bedchamber, Juliet asks the Nurse and her mother to let her spend the night alone. Clutching the vial given to her by Friar Lawrence, she wonders what will happen when she drinks it. If the friar is untrustworthy and is attempting to hide his role in her marriage to Romeo, she might die; or if Romeo is late for some reason, she might awaken in the tomb and 
go mad with fear. She has a vision in which she sees Tybalt's ghost, before toasting to Romeo and drinking the contents of the vial.

In the Classical Comics adaptation, the first panels of Act 4 Scene 3 are coloured by an orange glow, emanating from the candles in Juliet's room. As Juliet's concern grows, the previous warm, safe colouring turns darker; Juliet's face is shadowed as she looks at the vial and the knife which she intends to use if the potion does not work. Juliet's body is viewed from above as she lies on her bed, worrying about waking before Romeo arrives. The panel opposite shows a reflected image of Juliet's body in the same position, but shrouded in a tomb; her words loop around in a series of thought bubbles linking the two images. There is a marked contrast between the dark, cold tomb and the warm, candle-lit bedroom. The mood becomes more frightening as Juliet has a vision of ghosts within her room (Figure 1). This is a scary image as it preserves the same lifelike drawing used throughout the comic; the reader is shown the vision from Juliet's perspective, that is, in a way which appears real, rather than as an obvious dream or illusion. The irregular frames on this page differ from the highly regular grid pattern elsewhere indicating Juliet's confusion and fear.

\section{[INSERT FIG 1 HERE]}

Juliet's concern is evident from the start of this section in the Manga Shakespeare adaptation as she is shown hesitating as she goes to her room. When Juliet describes her fears that the friar has betrayed her, she is shown in a negative image, a black background with her outline and words in white, emphasising darkness of her thoughts, 'What if it be poison which the friar ministered to have me dead, because he married me before to Romeo' (Appignanesi and Leong, 2007: 143). As she lies in bed with her arms folded over her body, her stiff posture makes her fears clear and, once more, her words are in white text on a black background showing her disturbed state of mind.

In contrast to the scary image presented in Classical Comics, here Juliet's vision of Tybalt's ghost is shown merely by a panel containing his photograph and the words, 'where Tybalt lies festering in his shroud' (Appignanesi and Leong, 2007: 144). Juliet's sorrow over Tybalt is shown simply by tears in her eyes. Perhaps unexpectedly, this manga adaptation plays much less on the supernatural elements of this scene. Instead of presenting a graphic image of Juliet's visions, it leaves it to the reader to fill the gaps left by the more quotidian images 
and imagine what is in Juliet's mind at this point. There is a blank panel, marking a reflective pause, before she toasts Romeo and drinks the potion. Immediately after are two panels with Juliet's face, the first an ordinary drawing, but with a blank expression, and the second a negative panel with a shocked expression as the potion starts to work and she reacts to it. The comic then cuts to a picture of her hand dropping the vial. While Juliet's' reaction to taking the potion would usually be important in a stage production, Manga Shakespeare is the only adaptation where this is shown in detail; in the other comics, it remains in the gaps between panels and it is left to the reader to imagine the precise effects of the potion on Juliet. A shadowed image then shows Juliet falling onto her bed, her role as the heroine of the story emphasised by her long hair flying backwards.

At the start of Act 4 Scene 3 in The Manga Edition, Juliet looks scared and lonely as she says goodnight to her nurse and mother. This character looks younger and more vulnerable that the Juliets of the other comics studied. Panels showing close up views of Juliet's face, hands and her pocket with the vial further indicate her fear and worry; she is slowly moving closer to taking the potion, but has to work to overcome her fears first. When she explains her concern that the friar has betrayed her, or that she will wake before Romeo arrives, we do not see Juliet herself, just too very dark panels containing speech bubbles with wavy edges indicating fear: 'How if when I am laid into the tomb, I wake before the time that Romeo come to redeem me? There's a fearful point' (Sexton and Lin, 2008: 129). As in Manga Shakespeare, in this adaptation, it is left to the reader to imagine what is in Juliet's mind at this time from her reactions and facial expressions. She is shown trying to shake the images of Tybalt's ghost out of her head, but it is left to the reader to determine what these look like. In this adaptation, taking the potion is highlighted as a dramatic moment and comes as a contrast to the more tranquil panels which precede it. There is a blast of light as Juliet toasts Romeo and drinks before swooning on to the bed as an archetypal heroine with her hair spread out around her.

Hinds' adaptation of Act 4 Scene 3 is relatively short covering a double page spread, but this allows an intense focus on Juliet's emotions. The scene is noticeably less melodramatic than in other versions, but the significance of the experience for Juliet is emphasised nevertheless. The verso is a full page illustration of Juliet regarding the vial of potion (Figure 2) with insets showing the immediately preceding action as she enters her room and locks the door, isolating herself from her family. Juliet's fears appear in staccato phrases, suggesting 
trepidation, within black speech bubbles with white writing: 'I have a faint, cold fear...thrills through my veins...that almost freezes up....the heat...of life' (Hinds, 2013: 102). Again, in this adaptation, the use of negative images indicates Juliet's fear and the intensity of her emotions. It is noteworthy that the only other point when Hinds uses this technique is when Juliet discovers that Romeo is dead. At the top of the facing page, we see just one of Juliet's eyes, wide with fear as she considers the possibility that she will wake before Romeo arrives to save her. Wordless panels then follow, decompressing time, as Juliet slowly uncorks the potion. At this point, her fear appears to have abated as she looks serene while toasting Romeo. Unlike the other adaptations, Hinds' Juliet does not swoon as a romantic heroine, but is simply shown lying on her bed with arms crossed in imitation of a conventional burial position and with an apprehensive expression.

\section{[INSERT FIG 2 HERE]}

\section{Act 5 Scene 1: Romeo learns of Juliet's 'death'}

In Mantua, a cheerful Romeo describes a happy dream about Juliet he had the night before. His mood quickly changes when Balthasar arrives with news that Juliet was found dead that morning. Shocked, Romeo writes to Montague saying he will return to Verona that night. Once Balthasar is gone, Romeo visits an apothecary to buy a vial of poison. Once alone, Romeo declares that he will go to Juliet's tomb and kill himself.

The Mantua depicted in the Classical Comics adaptation appears a lush, peaceful place and at the start of Act 5 Scene 1 Romeo looks relaxed as he fishes and recalls his dream about Juliet. Romeo quickly becomes animated when he sees Balthasar however; he is clearly keen for news and bombards Balthasar with questions before the messenger has dismounted his horse. We see a close up of Balthasar's face with a clearly concerned expression as he tells Romeo what has happened in his absence. Behind is a cut away showing Juliet's body being taken into the vault. This demonstrates an interesting feature of comics as the image which Balthasar has in his mind while he is talking to Romeo (and the reason for his solemn expression) can be shown concurrently, in the same frame. Romeo reacts immediately, and angrily, as he throws his rod away. Following his initial outburst, however, Romeo restrains his feelings. It becomes more difficult to comprehend the emotional state of this controlled, 
impassive Romeo in comparison to the more expressive Romeos in other adaptations described below. He shows little obvious emotion; even when says he intends to use the poison at Juliet's grave, his face is impassive.

The modern day Mantua of Manga Shakespeare is a property development site and Romeo is first seen sitting outside a caravan. In contrast to the other adaptations, this scene is set at night. Balthasar's arrival by car indicates the faster pace of this version. Another noticeable difference is that Romeo appears much more morose and also more anxious prior to Balthasar's arrival, as he checks his mobile phone for messages from Verona. At first, Romeo hopes that Balthasar's arrival brings good news, indicated by the bright light surrounding his car. But of course this is not the case. The ominous words, 'then she is well and nothing can be ill' (Appignanesi and Leong, 2007: 155) are positioned below an image of Romeo and Balthasar, but the text is separated from the frame, with the speech bubbles isolated from the figures against black background, thus emphasising the seriousness of the message and its implications which will reach far beyond the two characters present.

Romeo's shock is clearly signified by a negative image of his face which slices diagonally through the scene; he appears dumbfounded. Romeo's agony on receiving the news is shown from three different perspectives in same frame, something which would not be possible in a theatre(Figure 3). Romeo slowly recovers from the initial shock and the next panels show him looking up at the stars, and then rising. This series of four panels contains no words and relatively little movement, the decompressed storytelling indicating the slowed pace of action as time seems to stop for Romeo.

\section{[INSERT FIG 3 HERE]}

The pace then quickens again as Romeo decides to act. A close up of his motorcycle handlebar and a 'Vvrooom' glyph slice through scene in an expanding triangle before Romeo roars away towards the vanishing point. Romeo's impulsiveness and determination are apparent in the full page image of his speeding motorcycle. As he says, 'Juliet, I will lie with thee tonight' (Appignanesi and Leong, 2007: 158), there is a close up of his face, set and determined. In this complex image, there is also an outline of the apothecary, representing the goal in Romeo's mind. Again, this demonstrates the ability to show different perspectives 
simultaneously which is possible in a comic, but not in other types of adaptation such as the theatre.

As is the case elsewhere within The Manga Edition, the scene-setting drawings showing Mantua are not typical of manga illustrations but have a detailed, orderly appearance, similar to a film set or theatre backdrop. As in other adaptations studied, Balthasar arrives looking downcast and sorrowful. He avoids looking at Romeo and we see only a close up image of his closed eyes as he speaks, indicating how difficult it is for him to relay this news, ' $O$ pardon me for bringing these ill news' (Sexton and Lin, 2008: 142). Romeo's expression is blank as he listens; he stares ahead, but his face is drawn with no mouth and few other features, an alternative way in which this illustrator has chosen to convey his shock. Romeo is drawn at an angle with a swirling pattern covering the frame, indicating his confusion and distress. At the far side of the pagean irregular speech bubble indicates a shaky voice. We see only his hand at this point, drawn with shaky lines indicating trembling (Figure 4). However he quickly moves from panic and confusion to anger and action, a shift which is shown by more angular frames and sharp-cornered speech bubbles. Romeo is drawn from a low perspective, giving the impression that he is genuinely challenging the stars. His swift movements, indicated by motion lines, and barked orders to Balthsar indicate his anger and determination to act.

\section{[INSERT FIG 4 HERE]}

Hinds' adaption also portrays Mantua as a peaceful retreat, where we first encounter Romeo sleeping on the grass. He lazily rises and recounts his dream. Hinds chooses to retain the full text here, emphasising the leisurely, relaxed pace of Romeo's life at this point. Of course, Balthasar's arrival abruptly changes the mood. Romeo's initial shock is apparent and the sweat beads show on his face as he clearly struggles to control his emotions. In contrast to the other adaptations, 'Then I defy you stars!' (Hinds, 2013: 107) is not a challenge shouted in anger, but a determined whisper, indicated by the broken outline of the speech bubble. As soon as Balthasar leaves, Romeo is free to display his true feelings. The wordless image of his head cracks into two before he puts his head in his hands in an image which splinters into fragments as his dreams are scattered. There is a close up of his tearful, but determined, face as he swears to travel to be with Juliet the same day. Hinds emphasises the speed with which 
Romeo reacts; his horse's hooves leave a trail of dust in their wake as he races across the countryside.

\section{Discussion}

The above analysis demonstrates the diversity of comic book adaptations of Romeo and Juliet. While following the storyline of the original, the examples studied differ markedly in the style of illustration; the way in which they abridge the text; and the setting, as well as the techniques they use to connect with the reader. But are these adaptations works worthy of study in their own right? Do they help young people to see Shakespeare's plays differently (as well as develop their understanding of comics as a medium)? Or are they merely simplifications, inferior versions whose only role is to make the text more accessible and engaging for less skilled readers? The following section attempts to answer these questions by reflecting on the analysis of the four texts presented above. Before making comparisons between each of these adaptations, the relationship between all four comic books and the original play is considered.

Despite Hutcheon's claim that 'multiple versions exist laterally, not vertically' (Hutcheon, 2012: xiii), suggesting that one text should not be privileged over the other, at a practical level there is evidence of a clear hierarchy in the ways in which many comic book adaptations are presented and marketed towards less able, or less engaged, students. This perpetuates the notion of adaptations as 'minor and subsidiary' works (Hutcheon, 2012: xiv). However, an examination of the four texts considered in this article clearly illustrates how comic book adaptations of Shakespeare have the potential to achieve much more than this. They can help students to develop a more in-depth understanding of the original text, in particular, an appreciation of the wide range of ways in which it can be interpreted. Critically, the presence of dual visual and textual codes does not, necessarily, make the story more explicit. On the contrary, comics leave room for imagination and interpretation, by means of gaps between frames for example. This can help students to develop these important, yet challenging skills. In addition, if students are required to compare several adaptations of different styles, this can help them to become 'knowing' audiences (Hutcheon, 2012), able to compare and make judgements about different adaptations. As they consider why a creator has chosen to present a scene in a particular way, they not only learn about play, but also develop visual literacy skills and an understanding of intertextuality. As Gibson (2009) argues, students benefit from studying several different interpretations of the text, making 
them aware that 'there is not one dominant vision or version'. Each of the adaptations studied presents the reader with an alternative interpretation and examining these may lead to students reaching a more in-depth understanding of the text. Furthermore, as Fox points out, 'comic-book texts have the marvellous ability to show rather than tell students how narratives work, how literary texts achieve their effects' (Fox, 2007: 95).

It is acknowledged that the techniques described above may appear elementary among comics scholars, but crucially, they are approaches which could be readily appreciated by most readers regardless of their previous experience of reading comics - an important consideration for teachers using comics within the classroom. More experienced students may be able to interpret features of the adaptations alone, while others may require support to help them identify and understand the meaning of the various techniques used. In addition, some features, such as indications of speed and the use of light and shadow, are likely to easily understood by most students, while more complex aspects, such as the positioning of text and perspective of the illustrations, require a greater understanding of the text and awareness of literary and visual conventions. When using comic book adaptations within a classroom, the same texts can be used support differentiation by task as students with differing levels of ability can access the texts on different levels.

It is noteworthy that, despite their differing approaches, all the texts studied focus on the emotions of the characters in these two scenes, taking advantage of the strength of comics as a personalising medium. For example, in Act 4 Scene 3, Juliet's facial expressions; her posture; the introduction of obvious hesitations or pauses; and disturbances to the normal style of illustration, such as the use of negative images or changes to frame shapes, all show her anxiety, reluctance and disturbed state of mind as she contemplates taking the potion. Similarly, in Act 5 Scene 1, the splitting and splicing of frames in several adaptations shows how Romeo's world is suddenly turned upside down when he hears of Juliet's death. Techniques such as shading and changes to the style of speech bubbles are also used to indicate changes in emotional state. This is potentially important for young people studying Shakespeare as the motivation and emotions of characters are not necessary obvious from text alone, especially for those new to Shakespeare. Furthermore, comics differ from other types of adaptation by frequently providing a direct link between the thoughts, or expressions, and the actions of characters in a way which is not possible on stage or even, 
with such immediacy, in film. One of the ways in which they achieve this is through the use of an inset to a panel indicating what a character is thinking or imagining.

Comics are able to show what happens between the lines of dialogue more effectively than basic stage directions in the original text. By showing the emotions of Romeo and Juliet so vividly and viscerally, for example, Juliet's visions and Romeo's shock and anger, the adaptations help the reader to see the scenes from the perspective of the characters thereby helping them to engage with the text more fully. However, the creator does not present the entire story to the reader. Rather, work remains to be done by the reader, who is left to fill the gaps between the panels in a way that makes sense to them. This requirement to complete the story themselves, rather than simply accept what the creator has provided, potentially leads to greater engagement and empathy. So, although the basic elements of the scene are depicted in all the comics, there are considerable differences between what is shown and what is omitted in each. For instance, some adaptations show the ghosts which appear to Juliet, but in most cases, reader is left to imagine these.

Comic adaptations of Shakespeare's plays may, therefore, help readers to empathise more fully with the play's characters and lead to greater depth of engagement. However, the visual, as well as textual, literacy skills required to decode comics means that they are far from just a medium to simplify the story. As comparing the four comics demonstrates, it is possible to view the play's characters in a variety of ways. To an extent, all four comics portray Juliet as a conventional, dependent, heroine, albeit one with a rebellious streak. She is relying on Romeo to arrive to save her and fears what will happen if he is delayed and she wakes before he arrives. The way in which Juliet swoons back onto her bed in three of the four comics reinforces this view. There is some variation, however. Juliet displays both vulnerability and determination in this scene and the way in which these two elements work together varies in each adaptation, with certain characteristics coming to the fore more strongly in some adaptations than others. Depictions of Romeo are even more diverse. Classical Comics has, perhaps, the least developed characterisation; in this adaptation it is difficult to discern Romeo's emotions beyond straightforward anger. In contrast, Manga Shakespeare's Romeo displays confusion, shock, anger, determination and impulsiveness during the same scene. This complexity in Romeo's reaction can be difficult to interpret from the text alone, and it is at points like this that comic book adaptations appear to come into their own. Even in a theatrical or film adaptation, it can be challenging for those new to the text to appreciate the 
character's complexity due to the speed at which the play is delivered. Comics have the advantage that the reader is able to control the speed of action and to dwell on frames they want to take more time to interpret. It is also possible to isolate emotions such as shock or confusion in a comic by 'freezing' it within a frame to emphasise a character's reaction in a way which would seem stilted in a play or film. A further difference between comics and theatre productions is that comic book adaptations are able to show the same scene from different perspectives simultaneously, by altering viewpoint, angle and distance of framing. This may also be an aspect which would be of value to some students as they consider what impact altering the viewpoint has on our interpretation of the scene.

Students may also benefit from the chance to engage in more challenging tasks focusing on the ways in which Shakespeare's text is used differently in each adaptation: the different ways in which it is abridged, but more significantly, how the text is integrated with the images to create a complete story in each comic. The ways in which a line of text is used by different creators can be revealing; it demonstrates how dialogue can be interpreted in a number of ways. The comics studied use techniques such as the position and shape of speech bubbles; style and colour of writing; and the relationship between the text and other elements of the image to provide 'clues' as to how the reader might interpret the words.

\section{Conclusion}

Comics have often seen by educators merely as, 'transitional, conduit material' (Dallaqua, 2012), or as March and Millard (2000) put it, 'a stepping stone to other kinds of reading'. However, this analysis has indicated that they have the potential to be much more, if used effectively. Comics are not merely a simplified format which caters for the needs of less able students as is often assumed. They also have much to offer more sophisticated readers. Ultimately, changing the settings or language of Shakespeare to something young people are likely to find more familiar or exciting does not, in itself, lead to real engagement with the plays. This only occurs when students become actively involved in the story and relate to the characters. Comic book adaptations are therefore important, not because they offer a means of simplification, but, much more significantly, because they require active participation on the part of the reader. Furthermore, just as the skills needed to study a film or theatrical adaptation differ from the literacy skills required to appreciate the original text, the study of comics adaptations requires visual literacy and intermedial skills to decode the 'language' used. Any teaching tool is only as radical as the way in which it is used. Currently, the ways 
in which comic book adaptations of Shakespeare are promoted focuses heavily on the needs of reluctant readers. However, if students are supported in exploiting the medium to its full potential, comics not only complement the original text, but offer a challenging alternative means of appreciating and developing an understanding of Shakespeare.

\section{References}

ABDO (nd), Graphic Shakespeare Series, Available at http://www.abdopub.com/shop/pc/configurePrd.asp?idproduct=16883 (accessed 16 Nov 2013).

Aiken, K. G. 2010, 'Superhero History: Using Comic Books to Teach U.S. History', OAH Magazine of History. 24(2), pp.41-47.

Allen, C. (1988) 'Louise Rosenblatt and Theories of Reader-Response', Reader, 20, pp.32-9.

Allen, K. and Ingulsrud, J. E. (2003), 'Manga Literacy: Popular culture and the reading habits of Japanese college students'. Journal of Adolescent \& Adult Literacy 46(8), 674-683.

Appignanesi, R. and Leong, S. (2007), Manga Shakespeare: Romeo and Juliet, London: SelfMadeHero.

Austen, C. and Larroca, A. (2004), Uncanny X-Men Volume 5: She Lies With Angels. New York: Marvel Comics.

Bamford, A. (Ed.). (2003). The visual literacy white paper, Available at http://www.adobe.com/uk/education/pdf/adobe_visual_literacy_paper.pdf (accessed $25 \mathrm{Apr}$ 2014)

Barthes, R., Extract (Readerly and Writerly), pp. 3 - 16. S/Z. Trans. Richard Miller. (Oxford: Basil Blackwell, 1974), Available at http://vogmae.net.au/intmedia/pubs/BarthesExtract.pdf) (accessed 25 Apr 2014).

Board of Studies New South Wales (NSW) (2004), Information for Parents and the Community about the Mandatory Courses in Years 7-10, Available at 
http://www.boardofstudies.nsw.edu.au/syllabus_sc/pdf_doc/info_parents_710_mandatory.pdf (accessed 26 Nov 2013).

Chute, H. (2008), 'Comics as literature? Reading graphic narrative', Publications of the Modern Language Association of America (PMLA), 123, pp.452-465.

Dallacqua, A. K. (2012), 'Exploring Literary Devices in Graphic Novels', Language Arts, 89(6), pp.365-378.

Department for Education (2013), Secondary National Curriculum until 2014, English: Range and content. Available at http://www.education.gov.uk/schools/teachingandlearning/curriculum/secondary/b00199101/ english/ks3/programme/range (accessed 16 Nov 2013).

Eisner, W. (1985) Comics and Sequential Art. Paramus, NJ: Poorhouse Press.

Ellis, J. (1982), 'The literary adaptation, an introduction', Screen, 23(1), pp. 3-5.

Fox, C. (2007), 'History, war and politics: taking 'comix' seriously', in V. Ellis, C. Fox and B. Street (eds.), Rethinking English in Schools, London: Continuum International Publishing, pp. 88-101.

Franco, C. (2011), The Cross-Media Journey of Muddle Earth: Design, Narrative and Brand Consistency in Game Adaptation, Available at http://transmediabooks.wordpress.com/mathesis-the-cross-media-journey-of-muddle-earth/ (accessed 5 June 2014).

Gerde, V. W. and R. Spencer Foster. 2007. 'X-Men Ethics: Using Comic Books to Teach Business Ethics', Journal of Business Ethics, 77, pp.245-58. doi: 10.1007/s10551-006-9347-3

Gibson, M. (2009), “"The War of the Worlds?” Classics, comics and ways of thinking about adaptations'. NATE Classroom 9 (Autumn), pp.11-13.

Gibson, M., 2008. "'So what is this mango, anyway?" Understanding manga, comics and graphic novels', NATE Classroom 5 (Summer), pp.8-10.

Groensteen, T. (2007) The System of Comics. Jackson: University Press of Mississippi. Hatfield, C. 2005. Alternative Comics: An Emerging Literature. Jackson MS: University of Mississippi. 
Hinds, G. (2013), Romeo and Juliet, Somerville, MA: Candlewick Press.

Hinds, G. (2010), The Odyssey, Somerville, MA: Candlewick Press.

Hinds, G. (2009), King Lear, Somerville, MA: Candlewick Press.

Hinds, G. (2008), The Merchant of Venice, Somerville, MA: Candlewick Press.

Hinds, G. (2007), Beowulf, Somerville, MA: Candlewick Press

Hosler, J. and Boomer, K.B. 2011. 'Are Comic Books an Effective Way to Engage

Nonmajors in Learning and Appreciating Science?', CBE Life Science Education 10(3), pp.309-317.

Hutcheon, L. (2012), A Theory of Adaptation ( $2^{\text {nd }}$ ed.), London: Routledge.

Iser, W. (1989). Prospecting: From reader response to literary anthropology. Baltimore, MD: Johns Hopkins University Press.

Labio, C. (2011) 'What's in a Name? The Academic Study of Comics and the 'Graphic Novel', Cinema Journal, 50(3), 123-8.

Lamb, C. and Lamb, M. (1994) Tales from Shakespeare, Ware, Herts: Wordsworth Editions Ltd

Lanier, D. (2010), 'Recent Shakespeare Adaptation and the Mutations of Cultural Capital (Forum: After Shakespeare on Film)', Shakespeare Studies, 38, pp. 104-13.

Lefevre, P. (2010). 'Intertwining verbal and visual elements in printed narratives for adults'. Studies in Comics, 1, 35-52.

Lewis, A.D. (2010), 'The shape of comic book reading', Studies in Comics 1(1), pp71-81.

Mairowitz, D.Z., Dostoevsky, F. and Korkas, A. (2009), Crime and Punishment (Illustrated Classics): A graphic novel, New York: Sterling.

Marsh, J. and Millard, E. (2000), Literacy and Popular Culture. London: Paul Chapman McCloud, S. (1994) Understanding Comics: The invisible art. New York: Harper Collins. 
McDonald, J., Volley, W., Devlin, J., Campbell, J., Wheeler, J. and Placentino, J. (2009), Romeo and Juliet: The graphic novel (original text), Towcester: Classical Comics Ltd.

Myklebost, S.A. (2013), 'Shakespeare Manga: Early- or Post-modern?', ImageTexT 6(3), Available at http://www.english.ufl.edu/imagetext/archives/v6 3/myklebost/ (accessed 16 Nov 2013).

Neill, F.V. (2013), 'Interface Rhetoric in Shakespearean Comics: A Study of the Effect of Interface on the Construction of Shakespeare's Plays', ImageTexT 6(3), Available at http://www.english.ufl.edu/imagetext/archives/v6_3/neill/ (accessed 17 Nov 2013).

Pomfrett, S. (2011). 'Getting graphic', The Bookseller, Available at http://www.thebookseller.com/blogs/getting-graphic.html (accessed 28 Apr 2014).

Richardson, J. (2006). Analysing newspapers. An approach from critical discourse analysis. Basingstoke, UK: Palgrave Macmillan.

Sawyer, M. (1987). 'Albert Lewis Kanter and the Classics: The Man Behind the Gilberton Company'. The Journal of Popular Culture, 20, pp1-18.

SelfMadeHero (nd). MangaShakespeare.com Learning, Available at http://www.mangashakespeare.com/ (accessed 28 Apr 2014).

Sexton, A. and Lin, Y. (2008), Shakespeare's Romeo and Juliet: The manga edition. Hoboken, NJ: Wiley Publishing Inc.

Shakespeare Comic Books (nd), About Us, Available at http://www.shakespearecomics.com/about-us/ (accessed 16 Nov 2013).

Weaver, S. (2011). The rhetoric of racist humour. US, UK and global race joking. Farnham: Ashgate Publishing.

Work, M., Lee, S., Douglas, T. and Srisuwan, S. (2011). Romeo and Juliet; The War. Irving, TX: Viper Comics. 
i Small, cute representations of characters indicating they are acting in a humorous or childish way. 